\title{
Mathematics teacher retention and the role of Identity: Sam's story
}

\author{
Mellony Graven \\ School of Education, University of the Witwatersrand \\ Email: gravenm@educ.wits.ac.za
}

This paper provides a vignette of one teacher's identity transformation from a temporary teacher of mathematics to a professional mathematics teacher (with a long-term trajectory within the profession) during the course of his participation in an In-Service Education and Training (INSET) program. Thus the paper elaborates, from Wenger's (1998) social practice perspective, the role of identity (one of Wenger's four learning components) in teacher learning and teacher retention within the profession.

The vignette provides textured insight into the way in which Sam's identity transformation was pivotal in his learning through participation within INSET and other overlapping mathematics education communities. Furthermore, I argue that identity (learning as becoming) was a key component of learning that kept Sam in the profession of mathematics teaching. From Sam's vignette I argue that positive identity transformation should be one of the most important intended learning outcomes of INSET and as such needs deliberate and focused attention in the design and implementation of teacher education programs. I therefore conclude the paper with some implications of Sam's vignette for the design of mathematics INSET programs.

\section{Introduction}

Sam's vignette is taken from a broader longitudinal qualitative ethnographic study that focused on understanding the nature of teacher learning within INSET, at a time of major curriculum change (Graven, 2002). The sample for the study included ten senior phase teachers of mathematics, from Eldorado Park and Soweto (urban township) schools who volunteered to participate in a twoyear INSET program called PLESME (Program for Leader Educators in Senior Phase Mathematics Education). The sample can therefore be described as a small, purposive, opportunity sample in the sense that the PLESME teachers were not randomly selected but were volunteers from schools suggested by the districts. The teachers therefore are not 'typical' of the general population of mathematics teachers. The PLESME program is set in context below.

Wenger's (1998: 5) four components of learning provide the analytical framework for the study and for this paper. These components are: Meaning-learning as experience; Practice-learning as doing; Community-learning as belonging and Identity-learning as becoming. I supplement Wenger's four components of learning with a fifth component, namely Confidence-learning as 'mastery' (see Graven, 2004).

These components are 'deeply interconnected and mutually defining' (Wenger, 1998: 5). The focus on the component of identity, for this paper, should not imply that the other components are not also important for teacher learning and teacher retention. Indeed these components provide the basis for the development of Sam's strengthened mathematics teacher identity and his longer-term trajectory within the profession. The relationship between the components of meaning, practice, community and confidence to identity will be illustrated in Sam's story. The story will highlight the way in which learning (as changing identity) in relation to these components is enabled through Sam's ongoing participation within the PLESME community of practice and its overlapping communities.

\section{The context of Sam's story}

Sam's story occurs within the context of participating in the in-service Program for Leader Educators in Senior Phase Mathematics Education (PLESME), aimed at supporting teachers to make sense of the radical educational reforms they are expected to implement. South Africa's new curriculum (called Curriculum 2005), premised on a learner-centred, outcomes-based approach to education, was launched in 1997. Key principles include integration, relevance, learner-orientation, flexibility and critical creative thinking (National Department of Education, 1997). While the new curriculum has been revised (and ongoing 


\section{Mellony Graven}

revisions continue) these key principles have remained central to curriculum revisions. These curriculum changes provide the broader context within which Sam's learning occurs.

The initial design of PLESME included: weekly workshops; individual and group reflection sessions; classroom visits accompanied by the use of video to facilitate reflection and discussion; individual and collaborative practical activities to be done in school; and some written activities that accompanied practical activities. With time, other key practices, not part of the original design, evolved from within PLESME. For example, teachers sharing frustrations and resources, commenting on each other's videos of lessons and the inclusion of activities in which teachers were networked into the broader professional community of mathematics educators. PLESME included fieldtrips to various teacher centres, district offices and the offices of mathematics INSET organisations, mathematics education associations and curriculum development organisations. PLESME teachers worked collaboratively to provide input into various mathematics curriculum documents and curriculum review documents. In addition PLESME teachers attended mathematics education conferences such as the national conferences of the Association of Mathematics Education of South Africa (AMESA). At these conferences the teachers presented papers relating to mathematics teaching ideas and/or challenges confronted in implementing new mathematics curriculum ideas. Thus, in agreement with Grossman, Wineburg and Woolworth (2001: 953) PLESME worked with the assumption that 'successful forms of professional development must offer multiple corridors for participation'. Participation in broader professional networks was furthermore seen as a means of sustainability of teacher learning and participation within the field of mathematics education beyond PLESME.

While the participating teachers of PLESME came into the program as teachers of mathematics the majority of teachers had not studied or intended to become mathematics teachers. In interviews and informal discussions with PLESME teachers it became evident to me that the distinction between one's identification as a teacher of mathematics or a mathematics teacher was a substantive issue which demanded focused attention (see Graven, 2004). Thus, while all PLESME teachers were teachers of mathematics most were not mathematics teachers by training, identification or by choice. The challenge for PLESME was therefore to help teachers to 'become' mathematics teachers in terms of mathematical competence and confident identification with mathematics teaching as their profession.

PLESME responded to this by strengthening teachers' mathematical identities in two key ways. Firstly it focused workshops on mathematical activities aimed at enabling teachers to: explore familiar mathematics topics in more depth; explore new mathematics topics introduced by the curriculum; explore mathematics problems and topics in relation to South Africa's socio, political and economic context; and to explore what it means to teach all of these in a learner-centred way. Workshops thus developed mathematics content knowledge for teaching (Shulman, 1986) and always contextualised discussions of 'new' pedagogies within mathematical contexts. The second was to maximise teacher participation in broader mathematics education communities through participation in conferences and field visits to overlapping communities.

\section{How is identity interpreted for this paper?}

According to Lave \& Wenger (1991), learning is located in the process of co-participation and not in the heads of individuals; not located in the acquisition of structure but in the increased access of learners to participation, and it is an interactive process in which learners perform various roles. Lave and Wenger (1991) prioritise the importance of participation in the practices of a community and identity as primary features of learning. For them learning 'implies becoming a full participant, a member, a kind of person...' (p. 53) and is inseparable from a sense of identity.

Since participation in the practices of a community is essential for the development of identity (and therefore of learning) they refine the notion of community for the purposes of learning. They emphasise that to become a full member of a community of practice 'requires access to a wide range of ongoing activity, old-timers, and other members of the community; and to information, resources, and opportunities for participation' (Lave and Wenger, 1991: 101). From this perspective tools and techniques for learning are replaced with 'ways of becoming a participant' and 'ways of participating'.

Wenger (1998) characterises 'identity' as negotiated experience, community membership, learning trajectory, multimembership and as a relationship between our local and global ways of belonging to various communities. Thus, he argues that we define who we are through: our participation and by the way we, and others, reify 
ourselves; the way we belong to various communities; where we have been and where we are going, and by combining various forms of belonging in various communities.

Wenger's (1998) notions of learning trajectories, and ways of belonging and participating in various communities, are particularly key to the analysis of Sam's learning as changing identity. According to Wenger (1998: 155), 'as trajectories, our identities incorporate the past and the future in the very process of negotiating the present... Learning events and forms of participation are thus defined by the current engagement they afford, as well as by their location on a trajectory.' Sam's story will illustrate the way in which participation in PLESME opens up new possibilities in relation to professional trajectories and ways of being.

\section{Why focus the analysis of Sam's learning on the transformation of identity?}

Identity is seldom the focus of In-Service Education and Training (INSET) or the focus of research on INSET. I hypothesise that many INSET providers view identity transformation as possible by-products of INSET rather than part of the core business of INSET. While designers and providers of INSET might hope that through INSET teachers will form positive ways of participating in and belonging to various related communities and hope that teachers will change who they are, their focus is usually restricted to changing what teachers know and do. This is possibly because designers and providers of INSET view teacher identities (and their related identification and alignment to various communities) as being less controllable and less measurable than say teacher meanings and teacher practices.

Wenger (1998) himself notes that we can design teacher roles but we cannot design the identities that will form in uneven ways. But Wenger (1998: 9) also notes that we need to reflect on all aspects of learning 'when we choose to meddle with it on the scale which we do today'. INSET, as we will see in Sam's story, 'meddles' with teacher learning in relation to teachers' identities and their forms of participation in various communities. Thus whether we view identity as a central component that should be a focus of the design and provision of INSET or whether we see it as a by-product of a focus on practice and meaning, reflection on how this component interacts with teacher learning is essential.

\section{Methods of data collection}

As explained above, the INSET program PLESME provided the empirical field for the study and the sample included ten teachers who participated in the program. In PLESME I wore two hats. Firstly, I was the co-ordinator of PLESME. This was my full time vocation and I was accountable to my organisation, the university, the steering committee, donors, teachers and schools on the value and 'success' of the project. At the same time, I was a researcher in the process of conducting research on the nature of mathematics teacher learning in relation to INSET within the context of rapid curriculum change. This duality of roles meant that I was both an 'observer participant' and a 'participant observer'. Working closely with teachers in PLESME helped give form to the research and the research process and enabled more sensitivity and reactivity by myself in PLESME.

This study adopted a relatively longitudinal, qualitative ethnographic approach and the data collected by myself as the researcher included: teacher interviews, teacher questionnaires and classroom observations for each of the participating teachers. These took place approximately every six months throughout the two-year period of the INSET. This data was supplemented with ongoing journal entries. While I collected data on all 14 participating PLESME teachers, data analysis and the write up of the broader research study focused on ten teachers (see Graven, 2002). These teachers were chosen because full data sets over the two-year period were available for them. I did not have full data sets for the other four teachers since they had either started late or did not teach mathematics at the senior phase (grades 7-9) at the time of the study. While the data analysis for all ten teachers revealed learning in relation to changing identity (Graven, 2002), Sam's story was chosen for this paper because of his focus on his evolving mathematical identity throughout his description and explanation of his learning.

The two primary sources of data that I use in this paper are interviews and questionnaires. There were, over the two-year period, four sets of interviews that all related broadly to teachers' understanding and practice of the new curriculum and teachers' understanding of their process of learning as related to PLESME. Interviews were semi-structured in the sense that they were conversations stimulated by a set of questions and probes. All interviews were conducted with teachers individually in an unoccupied classroom 


\section{Mellony Graven}

or office and were recorded for transcription. Questionnaires asked similar questions to those in interviews and were useful in the sense that they provided another context for teachers to reflect on their practice

\section{Sam's story}

At the start of PLESME in January 1999 Sam taught primarily accountancy and business economics at a high school in Eldorado Park. Sam had taught mathematics to grade 8 and 9 students in previous years but due to redeployments of teachers at his school he was forced to 'fill the gaps' and only taught one mathematics class. Sam expressed that his intention was to remain in teaching for approximately five years and then move into a career in computers.

\section{The strengthening of Sam's identity as a mathematical being}

At the start of PLESME in January 1999 Sam struggled to make mathematical sense of various new mathematics specific outcomes as outlined in the new curriculum. For example:

With (specific outcome) number $4^{1}$, 'critically analyse how maths relationships are used' - that would be important for one of the outcomes, for instance specifics will come in here, where you can analyse specifics in certain diagrams and so on... As regards cultural products and so on you need mathematical things, shape, space and time... Space and time? Nothing comes to mind. It is too broad (Sam Interview, January 1999)

By the end of PLESME Sam indicated both an enthusiasm and a strong ability to explain, with the use of examples from his classroom teaching, the mathematical meaning he made of the new mathematics specific outcomes. Especially interesting in Sam's response to these outcomes two years later is the evidence of the development of a strong mathematical gaze on the world. This mathematical gaze emerged both in terms of

\footnotetext{
${ }^{1}$ Curriculum 2005 outlined 10 mathematical specific outcomes (SOs). These included outcomes which contextualised mathematics in social, political, economic, 'cultural' and historical contexts. Since these outcomes were new to teachers (i.e. they were largely absent in the previous curriculum), understanding these outcomes in relation to what they meant for teaching mathematics was a focus of the first six months of PLESME workshops. In the excerpts included here Sam is responding to his reading of:

SO4: "Critically analyse how mathematical relationships are used in social, political and economic relations."

SO8: "Analyse natural forms, cultural products and processes as representations of shape, space and time."
}

finding ideas for mathematics teaching and as a critical mathematics gaze for approaching various aspects of his life such as checking the tax on payslips and comparing prices of different size packages in a supermarket. The following abbreviated extract indicates the development of Sam's mathematical gaze (with a critical stance) and of his strengthened identity as a person with mathematical expertise:

Okay this is one (referring to Specific Outcome number 4) I use quite a lot. It's where for example in our NUE (National Union of Educators) book one of the teachers came to me and said 'listen they paid me wrong'... So she asked me now how much money. I said 'okay this is the formula from the NUE book so let's see how much she has been paid' and we went through that... and we sent a letter through... and the same with our increases they came to me and asked me how so so and so... And so when I get my pay-slip and I work out my money, the taxes, everything is fine. So I have the skill and the knowledge that they paid me correct... Cricket as well if you look at your cricket scores... Your bleach is normally $750 \mathrm{ml}$, now it gets to 1 litre and that changes your value...

MG (myself as interviewer): OK so you think about that when you are buying the stuff?

Sam: Ya

MG: Okay, in your teaching, what does this outcome mean for your learners?

Sam: Like the cell phone project we went through it and they've seen what happened when you collect your data in order to make an informed judgement... With my surface area and volume when they wrapped their presents... Even some of the taxi drivers I have seen them use a graph pasted on dashboard (Sam Interview, November 2000)

This excerpt shows that Sam clearly became a more confident 'mathematical thinker' who observed the world through a mathematical lens and used this lens to find ideas for mathematics teaching. Furthermore the excerpt describes the way in which Sam uses mathematical skills to critically analyse aspects of his environment:

In order for me to question and change something I need to know it. If I don't know it on a maths level I can't change it. Maybe that is why banks have lowered 
their interest rates now because someone questioned the interest... (Sam Interview, June 1999)

\section{Sam's changing identity in relation to his changing practice}

Sam's strengthened mathematical gaze and understanding of the various mathematical outcomes of the new curriculum influenced (and of course was influenced by) Sam's changing practice within teaching. In July 1999 Sam applied for a mathematics post at a school outside of Eldorado Park (a well respected school in a predominantly white area). Here he taught grade 8 and 9 mathematics classes and implemented various new curriculum ideas, contents and pedagogies which he had engaged with in PLESME. At the end of the first year of PLESME (November 1999) Sam explained his changed practice as follows:

I have experimented with groups' sizes etc. Pupils talk and explain to their peers. It is not so "quiet" in my classroom. I make better notes after and during the lessons. It is not so teacher-centred anymore. I will listen to different ways of getting to an answer. I know my pupils' strengths and weaknesses and I can plan lessons accordingly. I know in what direction to move with my pupils. I know where they are - where to go and how I am going to get there (Sam Questionnaire, November 1999).

In the second year of participating in PLESME Sam's confidence in his teaching continues to grow. To illustrate Sam's increasing confidence over time and the development of his new 'way of being' in his classroom, I compare Sam's descriptions of his classroom practices in July 2000 to his description above. Note that by July 2000 Sam had been participating actively in PLESME for 18 months. Sam had thus spent 18 months debating various contents and methodologies espoused in the new curriculum and had experimented with them extensively in his teaching practice. By this time Sam had also been teaching at his new school (as a mathematics teacher) for a year and his confidences within his school were clearly emerging. Sam's November description above clearly indicates changes in what Sam knows and what Sam does in the classroom. His increasing confidence in adopting more learner centred practices is implicit in his last three sentences which all begin with "I know ...'. Thus Sam's explanation of his learning is largely explained in relation to the components of meaning and practice. However, in July 2000, eight moths later, Sam's description of his changing practices moves beyond what he knows and does to explicitly include a range of affective terms, such as relaxed, better, confident and enjoy, which describe his changing way of being in the classroom.

As a teacher I am much more relaxed...

Link maths to children's everyday lives. I reflect on my lessons afterwards. Try new and different things all the time. I am ten times better and confident than what I was two years ago. I enjoy my "maths" teaching so much "I will probably do it for a long time to come" (Sam Questionnaire, July 2000).

The time that elapsed between the two interviews enabled Sam to develop more experience both in terms of engaging in discussion about the new curriculum as well as in teaching it. Sam's descriptions of his changing classroom practice above indicate changing forms of participation and practice on both his part and on the part of his learners within the classroom community. For example, Sam's learners are encouraged now to explain their own methods resulting in increased engagement and more central participation ${ }^{2}$ in class. Sam is more confident and relaxed in class and he now sees teaching as a learning process where he reflects on his lessons in order to adapt them and try new things in the future.

\section{Sam's changing identification by others in various communities in which he participates} Sam's changing practices and new 'way of being' in the classroom results in (and is also the result of) a new identification within the school community.

For example, Sam explains:

I must say you get your status as well in your community, it's one of the good things, even with your children, your children see you as for example the other classes I don't teach, the children say $\mathrm{Mr}$ (Sam) will you teach us next year for maths please? (Sam Interview, June 2000)

This strengthened identity as a competent mathematics teacher who is able to implement new curriculum ideas and practices impacts on Sam's practice as a mathematics educator beyond his

2 Central participation as opposed to peripheral participation which might involve a more passive or 'quieter' class where learners follow teacher methods rather than share their own ideas. This move to more central participation goes hand in hand with the movement from teacher-centred to more learner-centred practices. 
classroom and hence on his identification within the broader education community. For example, Sam explained in interviews how he wished to work with other teachers to develop a mathematics project based on the 1999 elections, and added 'I can do this because I know the outcomes from your (PLESME) course' (Sam Interview, June 1999). He explained how he had been asked to develop and co-ordinate learning materials and projects (related to various new curriculum outcomes) for all grade 8 and 9 classes in his school. Sam further explained how his confidence influenced his interaction with others about mathematics education:

Like when you have your syllabus and your HOD (head of department) will tell me I have to cover everything and then just to please him I must cover everything but now I am at the point where I can say listen there's no need for me to cover everything. I've got the confidence and I say listen this is the time what I have, this is what's important...(Sam Interview, November 1999)

I can share my ideas with other teachers from other schools. I can join in with the OBE (Outcomes-Based Education) thing and express my opinions...Yah, even when I am talking to parents now, its now where, how can I say, I can actually come up with examples and explain them' (Sam Interview, November 2000)

Sam attributed his increased confidence to his belonging and alignment to his PLESME group which allowed him to answer questions from others 'and give them a good argument based on my pool of people I work with' (Sam Questionnaire, July 2000). The quotes above are indicative not only of Sam's increased participation in the practice of sharing ideas with others but also illustrative of shifting relations between Sam and members of the communities in which his participation increases. Sam is now able to challenge others' views and takes more ownership of his classes. Sam increasingly identifies himself as a professional with the authority to make decisions in his classroom and to share information and ideas with others. At the same time others at his school, noting his competence and confidence, ask Sam to take on more responsibility within the mathematics department.

Thus in a dialectical relationship Sam's strengthened identity as a more competent and knowledgeable professional leads to changing forms of identification within his classroom community and his school community. This in turn reinforces and strengthens the development of his identity as a more confident teacher with a greater investment in the profession of mathematics teaching.

\section{Sam's identity transformation and his multimembership in various communities}

As described earlier, alignment to the professional mathematics teachers association AMESA was seen as an important part of PLESME since it provided the opportunity for inducting teachers into the broader profession of mathematics education and extended the opportunities for teacher learning beyond the lifespan of PLESME through membership in other more permanent communities. Sam's engagement and alignment to the AMESA community was stated as a very important and enjoyable part of his learning. This is enthusiastically captured by Sam as follows:

I am not going "nuts." I have met people at AMESA who think like I do. What a relief...! I will present at this conference every year and will attend it every year. After five years of teaching this is the best thing I have experienced (Sam Questionnaire, July 2000)

This quote provides insight into the way in which participation in and belonging to a professional association, such as AMESA, reduces teacher isolation and provides a resource where teachers can engage with others about their ideas and their profession. It captures the importance of being able to engage with like minded people, to not feel so isolated within one's practice and to find a shared purpose with others. The quote also indicates Sam's trajectory into the future when he says that he will attend the conference every year. Furthermore participation in AMESA leads to Sam's changing identification by others in various communities.

Thus, in the same way as Sam's identity and identification in terms of his participation within his school community changed, people in the broader community of mathematics education began identifying Sam as someone with desirable expertise and enthusiasm. For example, at the end of 2000 Sam was invited to apply for a job as a mathematics INSET provider, he was asked by various mathematics educators to participate in their research projects, he was asked to give a presentation to mathematics teachers on his PLESME experiences at a regional mini 
conference, and so on. The following year this recognition by others in the community of mathematics education continued. Sam was offered the position of mathematics Head of Department at another school, he was asked to write pace setters for mathematics in the Further Education and Training Band (grades 10-12) and asked to make a teacher training video. All these examples are indicative of the changing status/identification awarded to Sam by the broader community of mathematics educators.

Thus Sam's changing recognition and identification also resulted in (and was the result of) an increase in Sam's participation in professional activities relating to the broader profession of mathematics education. This recognition led Sam to input into curriculum developments, trial curriculum materials, attend conferences, present at conferences, participate in discussions on current topical issues in mathematics education, develop learning materials and register for further studies in mathematics education.

\section{Reflecting on Sam's identity transformation from a temporary teacher of mathematics to a professional 'leader' mathematics teacher}

All of the above parts of Sam's story come together to illustrate a profound transformation in Sam's identity from someone who temporarily taught mathematics while on a trajectory out of teaching to someone who identified himself strongly as a fully participating member of the professional community of mathematics educators with a great deal of expertise and enthusiasm to offer this community. Thus Sam explained that his five-year plan to move out of teaching was replaced by his 'immersion' in the profession of mathematics teaching.

Yeah because my main ideas when I started teaching five years ago I said I'm just going to teach for five years and that is it. And then I am going to go into my computers, because I'm coming to the end of my five years and I still want to do it. The computers are a hobby now (Sam Interview, November 2000)

This immersion and Sam's new ways of belonging, ways of being and ways of participating in various communities kept Sam invested in the profession and was accompanied by a long term trajectory. Sam's strengthened identity and longer-term trajectory is accompanied by confidence, enjoyment and enthusiasm for the profession as is clearly captured by Sam in the following:
I'm a maths teacher. I can work at a fast pace. Instead of falling asleep, I'm busy and active, I calculate, I do what I do best, it's maths...It (participation in PLESME) makes me feel more secure in my job, where I can how can I say, it's equipping me for OBE (Outcomes Based Education) and so on and redeployments. I won't be the first on the (redeployment) list. Because if I am first on the list I can always go up to the GDE (Gauteng Department of Education) and try and train some teachers and, yaah, I get satisfaction out of this. To me I'm at the forefront of the change. It's one of my goals to be the best teacher, not just to get a salary (Sam Interview, June 1999).

Furthermore, as the above quote indicates, Sam identifies himself as a leader in the field of curriculum implementation and change. This is clear when Sam says, 'I can always go up to the GDE and try and train some teachers... I'm at the forefront of the change.' Similarly in a questionnaire of July 2000 Sam explains his strengthened identity as a confident and competent mathematics teacher who is ready to lead others in curriculum change:

I am ten times better and more confident than what I was two years ago. I enjoy my 'maths' teaching so much I will probably do it for a long time to come. I want to study and get my degree in maths education...I want to stay in the classroom...Because of PLESME I have options and I come to school with an even bigger smile... My mathematical sense has deepened. I can do lectures. I can conduct workshops. I think I am ready to work in Eldo's to help my fellow teachers to see what I have seen in maths education and maybe experience what I have experienced. I will present at this conference every year and will attend it every year (Sam Questionnaire, July 2000).

These excerpts above indicate the projection of Sam's identity as a mathematics teacher/educator and leader in this field that is beyond present time. Sam's utterances indicate a clear mathematical trajectory that prioritises mathematics learning in the present and the future. Sam's trajectory involves continuing to increasingly establish himself as a leader in the field through further studies, ongoing participation, presentations at 
mathematics education conferences and supporting fellow teachers. In this way we see that Sam's identity, as a trajectory, 'incorporated the past and the future in the very process of negotiating the present' (Wenger, 1998: 155). Thus, Sam's story concurs with the research of Grossman, Wineburg and Woolworth (2001: 996) who argue that communities provide opportunity for cultivating leadership where leadership is considered as "not a personality trait but an attribute of selfdevelopment in social relationships'.

At the end of 2000, when Sam was invited to apply to work in the field of mathematics teacher education, Sam had to weigh up the extent to which his identity was more aligned to teaching mathematics to learners or working as a 'leader educator' with mathematics teachers. In the end, Sam chose to remain in teaching, to register for the Bachelor of Science Honours in Mathematics Teaching degree and to postpone working as a 'mathematics teacher educator' for later. Sam qualified with his BSc Hons degree two years later and is currently the mathematics HOD at a school in Eldorado Park. He continues to be involved in mathematics education activities which extend beyond his school.

Notice that in relation to Sam's imagination ${ }^{3}$ of both his immediate and his longer-term future, mathematics is explicitly foregrounded. I have not argued that Sam's story is 'typical' of all the teachers in PLESME. Teacher identities indeed formed in uneven ways as teachers adopted new roles in relation to the new curriculum and their participation in PLESME. The different trajectories of teachers were influenced by their mathematical and other histories. Sam's story was chosen because of his focus on his evolving mathematical identity throughout his description and explanation of his learning. Grossman, Wineburg and Woolworth (2001: 942) refer to the essential tension between 'professional development geared to learning new pedagogical practices and that devoted to deepening teachers' subject matter knowledge in the disciplines of instruction'. Indeed for some of the PLESME teachers the subject specificity of mathematics tended to be backgrounded in their explanations of their learning through participation in PLESME. However, all PLESME teachers, like Sam, explained their learning in PLESME in terms of

\footnotetext{
3 According to Wenger (1998: 173), identity involves 'belonging' to a community of practice. A central mode of belonging is 'imagination'. Imagination involves 'creating images of the world and seeing connections through time and space by extrapolating from one's own experience'.
}

changing ways of being, new ways of participating in various education activities, new forms of identification and forms of belonging within various communities. In addition several teachers adopted similar trajectories to Sam's in the sense that they abandoned their past plans to exit the profession and replaced these with trajectories which increased their investment in the profession through participating in further mathematics studies.

Sam, like other teachers in PLESME, linked his evolving identity to his participation and belonging in the PLESME community. For example, he noted that participation in PLESME made him feel more secure in his job and opened up new avenues, as captured by 'because of PLESME I have options'. Thus belonging to the PLESME community (and the overlapping communities which he participated in through PLESME) provides the supportive context within which Sam's trajectory and identity evolve. This leads us to ask: What key aspects in the design of PLESME supported Sam's (and other PLESME teachers') identity transformation?

\section{Conclusions}

In concluding this paper I reflect briefly on two ${ }^{4}$ key aspects of PLESME which Sam and other teachers highlighted as important in the formation of their strengthened identities as confident mathematics teachers with longer-term trajectories in the profession.

The first of these was a participatory approach to learning in which teacher professionalism was considered a key resource. The approach to learning that emerged within the PLESME community of practice was one that assumed that the participating teachers were professionals with a great deal of experience to input into discussions about the new curriculum. The new curriculum was new to all and PLESME would provide a community of practice in which teachers and presenters would jointly make sense of how the curriculum could and should be implemented. Each would bring a different type of expertise into the community. While the discourse of such an approach might sound obvious and hard to reject, it was clearly not an approach which teachers had encountered in other INSET contexts. Thus the majority of PLESME teachers, in describing their learning, highlighted the participatory approach and the professional identification they were

\footnotetext{
${ }^{4}$ While there are many other aspects that could be elaborated on, for conciseness, I have focused only on those which were most prolific in teacher utterances.
} 
granted in PLESME in contrast to approaches which 'dictated' what they should do. For example, Sam noted, "what I pick up is how different the GDE district treats us to workshops. Here we are seen as a professional... (Sam Interview, June 1999).

In Wenger's terms the participatory approach of the PLESME practice would allow for teachers to move from peripheral participation (as in the case of teachers' experiences of other workshops) to fuller participation in the PLESME community and other overlapping communities. Recall that for Lave and Wenger (1991: 53) learning 'implies becoming a full participant, a member, a kind of person ...'.

The second key aspect on which teachers focused was the support they obtained through belonging to the PLESME community and through their induction into other overlapping mathematics education communities. Both of these aspects were enabled by the long-term and small-scale design of PLESME. This design enabled teachers to become full participants and to develop a strong sense of belonging to the PLESME community. The small scale of PLESME allowed for strong relationships to develop between the members of PLESME and allowed for the inclusion of 'fieldtrips' and financial support for teachers' conference attendance. For all PLESME teachers, belonging to PLESME and to AMESA were noted as key enablers of their learning and their changing ways of being. This belonging enabled teachers to draw on the community for support and also provided credibility ${ }^{5}$ outside of the community for their thoughts and views on mathematics education. Sam's story clearly illustrates that: 'a community of practice is a living context that can give newcomers access to competence and also invite a personal experience of engagement by which to incorporate that competence into an identity of participation' (Wenger, 1998: 214) and for cultivating leadership.

Sam's vignette has illustrated the mutual definition and interconnectedness of Wenger's learning components: identity (learning as becoming), community (learning as belonging), practice (learning as doing), meaning (learning as

\footnotetext{
${ }^{5}$ Recall Sam explained that he could justify his arguments based on the pool of people he worked with (i.e. the PLESME community)
}

experience), and has also highlighted the centrality of confidence in this learning. The vignette furthermore reveals that Sam's strengthened mathematical identity increases his investment in the profession of mathematics education. This investment replaces his initial trajectory which involved exiting teaching and replaces it with a trajectory of ongoing learning and central participation within the field of mathematics education. As such his story highlights the importance of designing and implementing INSET in ways that enable teachers to positively transform their identities through providing them with 'access to a wide range of ongoing activity, oldtimers, and other members of the community; and to information, resources, and opportunities for participation' (Wenger, 1998: 101). While Sam's story is located within a mathematics INSET context I believe that similarly INSET in other learning areas should enable the investment and strengthening of teachers' identities in relation to the learning area that they teach.

\section{References}

NATIONAL DEPARTMENT OF EDUCATION (NDE), 1997, Curriculum 2005: Lifelong Learning for the $21^{\text {st }}$ Century, NDE, Pretoria

GRAVEN, M., 2002, Mathematics Teacher Learning, Communities of Practice and the Centrality of Confidence, Doctoral Dissertation, Faculty of Science, University of the Witwatersrand, South Africa

GRAVEN, M., 2004, "Investigating mathematics teacher learning within an in-service community of practice: the centrality of confidence", Educational studies in Mathematics 57(2), pp 177-211

GROSSMAN, P., WINEBURG, S. \& WOOLWORTH, S., 2001, "Toward a theory of teacher community", Teachers College Record, 103(6), pp 942-1012

LAVE, J. \& WENGER, E., 1991, Situated Learning: Legitimate peripheral participation, New York: Cambridge University Press

SHULMAN, L. (1986) "Those who understand knowledge growth in teaching", Educational researcher, 15(2), pp 4-14

WENGER, E., 1998, Communities of Practice: Learning, Meaning, and Identity, New York: Cambridge University Press 